\title{
Recurrence of hepatitis B and delta hepatitis after orthotopic liver transplantation
}

M R Lucey, D M Graham, P Martin, A Di Bisceglie, S Rosenthal, J G Waggoner, R M Merion, D A Campbell, T T Nostrant, H D Appelman

\begin{abstract}
The clinical course of 10 liver transplant recipients who had hepatitis B virus (HBV) and five recipients with $\mathrm{HBV}$ and D (delta) infection before transplantation is described. Six patients who underwent eight transplants died. The estimated one and two year survival rates in patients with HBV only before transplantation were $74 \%$ and $67 \%$ respectively. The estimated one and two year survival in patients with HBV and HDV infection beforehand was $100 \%$. Graft infection by HBV occurred in 8 of 10 patients infected with HBV only; and in 4 of 5 patients with previous HBV and HDV infection. There was a widely variable time from transplantation to the appearance of $\mathrm{HBV}$ markers in liver or serum, ranging from 6-331 days. Hepatitis D antigen (HDAg) appeared in three grafts very rapidly after transplantation at 4, 8, and 37 days respectively. Graft infection by HBV was accompanied by significant liver injury in six allografts in five recipients. In particular, there was a striking morphological appearance in five infected livers in which the hepatocytes became progressively enlarged and distorted as they accumulated huge amounts of hepatitis B surface and core antigens (HBsAg, HBcAg). These features were accompanied by pericellular fibrosis and cholestasis but little associated inflammation. This syndrome carried a poor prognosis. A gradual progression to cirrhosis occurred in one additional liver. Finally, recurrent HBV infection was a principal or a contributing factor in all deaths. The presence of $\mathrm{HBcAg}$ and inflammation in the native liver increased the risk of $\mathrm{HBV}$ induced tissue damage in the graft whereas HDV infection in the host liver seemed to reduce the risk of significant $\mathrm{HBV}$ induced tissue damage in the allograft. These data suggest that post transplant $\mathrm{HBV}$ infection is accompanied by a variety of changes in the liver allograft, some of which are unique to the transplanted liver and may result in impaired allograft function.

(Gut 1992; 33: 1390-1396)
\end{abstract}

While liver transplantation has become the treatment of choice in the developed world for many forms of serious acute and chronic liver diseases, its role in the management of liver disease caused by hepatitis B virus (HBV) and hepatitis D (or delta) virus (HDV) infection remains controversial. 'It has been observed that reinfection of the grafted liver by HBV either alone or with HDV is common..$^{1-5}$ However, the nature and severity of the liver injury associated with graft reinfection is variable. In this report we review the sequence of changes in liver allografts performed in a series of $\mathrm{HBV}$ surface antigen (HBsAg) positive patients, and describe the clinical and pathological factors that seem to influence the course of recurrent $\mathrm{HBV}$ infection.

\section{Patients and methods}

We studied all patients with $\mathrm{HBV}$ infection who underwent orthotopic liver transplantation at The University of Michigan Medical Center between June 1987 and October 1989. These patients were monitored at frequent intervals (1-3 months) by physical examination, measurement of biochemical tests of liver integrity and function, and serological tests for HBV markers. Our operative and immunosuppressive approach has been described elsewhere. ${ }^{6}$ All patients were managed initially with Minnesota antilymphoblast globulin, methylprednisone, and azathioprine with maintenance triple drug therapy consisting of cyclosporin A, prednisone, and azathioprine. Acute cellular rejection was treated by short courses of high dose corticosteroids or $\mathrm{OKT}_{3}$. Liver biopsy specimens were taken whenever rejection was suspected clinically and according to a protocol - usually at 7,14 , and 21 days, 6 months, 1 , and 2 years. One hundred and fourteen specimens were available for review, a median of 7 per patient.

Intravenous anti-HBs immunoglobulin Ig (HBIG, Abbott Laboratories) was administered intraoperatively $(50-125 \mathrm{cc})$ in 11 transplants, and in four of these postoperatively $(50-150 \mathrm{cc})$ also, according to a schedule of $10 \mathrm{cc}$ per day. Six transplants were not given cover by HBIG. Serum aminotransferase activities and bilirubin concentrations were measured by autoanalyser. Serum hepatitis B surface antigen was estimated by radioimmunoassay (AUSRIA II, Abbott, North Chicago, IL); hepatitis B e antigen (HBeAg) was assayed by enzyme linked immunoassay ( $\mathrm{HBeAg}$ test, Abbott Laboratories, North Chicago, IL); and HD antibody (HBDAb) was estimated by ELISA (Abbott, North Chicago, IL). HBV DNA was estimated in serum by dot-blot hybridisation as previously described. ${ }^{7}$ The minimal level of detection of this assay is $0.1 \mathrm{pg}$ HBV DNA per sample. Hepatitis $\mathrm{C}$ antibody (HCAb) was measured in stored sera using a radioimmunoassay kit (Ortho). Sections of formalin fixed native livers and liver allograft biopsy specimens were routinely stained with haematoxylin and eosin, trichrome, and periodic acid Schiff (PAS) with diastase. Immunohistochemical stains for $\mathrm{HBcAg}$ and $\mathrm{HBsAg}$ were performed using commercially available polyclonal antisera (Dako, Carpinteria, CA) and the avidin-biotin peroxidase complex technique. ${ }^{8}$ 
TABLE I Fifteen patients with hepatitis $B$ virus $(H B V)$ infection undergoing orthotopic liver transplantation

\begin{tabular}{lc}
\hline Gender $(M: F)$ & $13: 2$ \\
Median age (years) (range) & $38(14-64)$ \\
Median duration of disease (years) (range) & $5(0 \cdot 1-13)$ \\
Source of hepatitis: & \\
IVDA & 2 \\
Transfusion & 4 \\
Sexual contact & 1 \\
Unknown & 8 \\
Preoperative hepatitis markers: ${ }^{\star}$ & $15 / 15$ \\
HBsAg & $8 / 15$ \\
HBeAg & $2 / 11$ \\
HBV-DNA & $4 / 14$ \\
Anti-HD Ab & $10 / 12$ \\
Anti-HC Ab & \\
Liver biopsy/hepatectomy specimen: ${ }^{\star}$ & $14 / 15$ \\
Cirrhosis & $1 / 15$ \\
Massive necrosis & $15 / 15$ \\
HBsAg & $9 / 15$ \\
HBcAg & $5 / 11$ \\
HDAg & \\
\hline
\end{tabular}

IVDA = intravenous drug abuser

${ }^{\star}$ Denominator indicates numbers tested.
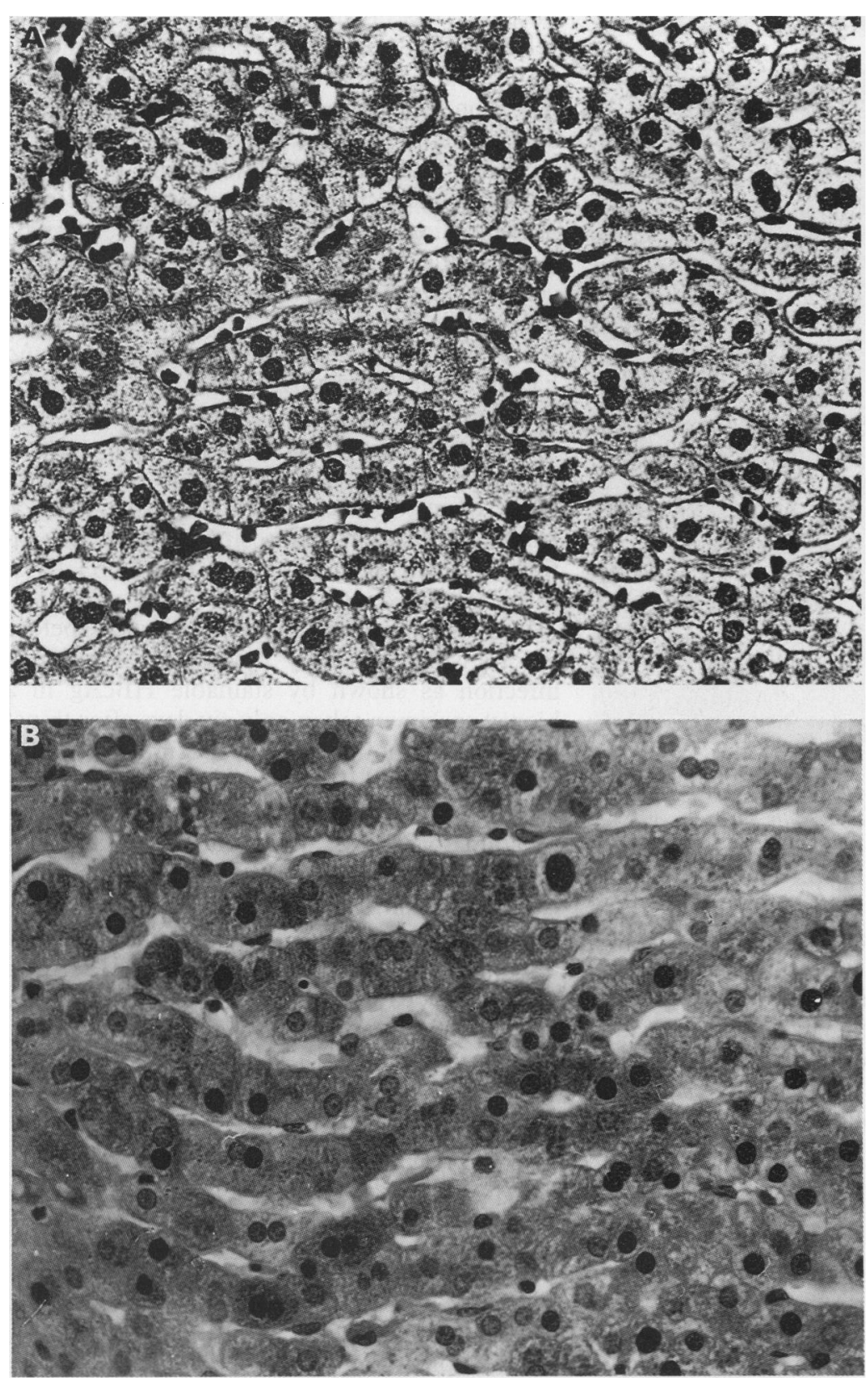

Figure 1: (A) Liver cells have inductive changes and form rigid cords in this biopsy specimen one month after transplant. This appearance in haematoxylin and eosin sections correlates with early stages of hepatitis $B$ virus antigen accumulation. (Original magnification $\times 400$ ).

(B) Immunohistochemical stain for hepatitis $B$ core antigen in the same biopsy specimen. There is cytoplasmic as well as nuclear staining for core antigen. (Original magnification $\times 400$.)
TABLE II Outcome of orthotopic liver transplantation in 15 patients with hepatitis $B$ virus $(H B V)$ alone or with hepatitis $D$ virus $(H D V)$

\begin{tabular}{lcc}
\hline & $H B V$ & $H B V$ and $H D V$ \\
\hline No of patients & 10 & 5 \\
No of transplants & 12 & 5 \\
Duration of follow up (days) & 445 & 936 \\
$\quad($ median (range) & $(111-1174)$ & $(594-1110)$ \\
Alive & 5 & 4 \\
Dead & 5 & 1 \\
1 Year survival & $73 \%$ & $100 \%$ \\
2 Year survival & $67 \%$ & $100 \%$ \\
Recurrence of HBV & 8 & 4 \\
Recurrence of HDV & - & 3 (of 4 tested) \\
Cirrhosis/fibrosis & 2 & 0 \\
Ground glass hepatocytes & 5 & 3 \\
Fibrosing cholestatic hepatitis & $4^{\star}$ & 0 \\
\hline
\end{tabular}

*Occurred twice in successive allografts in one patient.

HDAg was detected immunohistochemically using modified technique of Recchia et al. ${ }^{9}$ The parafin embedded specimens were first digested with proteinase $\mathrm{K}$ and subsequently coated with $1 / 100$ dilution of anti-delta antibody positive human serum and then with a rabbit anti-human IgG (1/16 diluted, Dako, Accurate Chem). After this, the specimens were treated with diaminobencidine tetrahydrochloride-hydrogen peroxide mixture and haematoxylin staining was subsequently undertaken. Liver biopsy samples were read under code by two observers (DMG and HDA) except for HD antigen staining which was read under code by ADB and PM.

\section{Results}

The 15 patients studied are described in Table I. Chronic disease was present before transplant in 13 , with a median known duration of HBsAg carriage of 48 months. Two patients presented with an acute syndrome, one of whom was HDV infected. Since the explanted liver of the latter patient was cirrhotic, it is likely that this represented acute, HDV induced decompensation preceded by clandestine chronic HBsAg carriage. The source of $\mathrm{HBV}$ infection was unknown in eight patients. The remainder had acquired HBV by intravenous drug use, transfused blood products (including one patient with haemophilia B previously reported), ${ }^{10}$ and presumed sexual contact. No patient had primary hepatocellular carcinoma.

The preoperative $\mathrm{HBV}$ and $\mathrm{HBD}$ serology and hepatectomy findings are summarised in Table I. All patients had $\mathrm{HBsAg}$ in serum, eight were HBeAg positive, and two were $\mathrm{HBV}$ DNA positive. HBsAg was shown immunohistochemically in the hepatectomy specimen from 13 patients; seven native livers were $\mathrm{HBcAg}$ positive as well. When these data were combined and the presence of at least one of the following (serum $\mathrm{HBeAg}$, serum HBV DNA, liver $\mathrm{HBcAg}$ ) taken to indicate viral replication, markers of viral replication were observed preoperatively in 13 of 15 patients. There was evidence of HDV infection in five patients, each of whom was positive for HDAb in serum and HDAg in liver.

Eight of the 10 patients with previous $\mathrm{HBV}$ infection alone developed serum $\mathrm{HBsAg}$ after transplantation. The median interval from transplantation to the presentation of serum HBsAg 

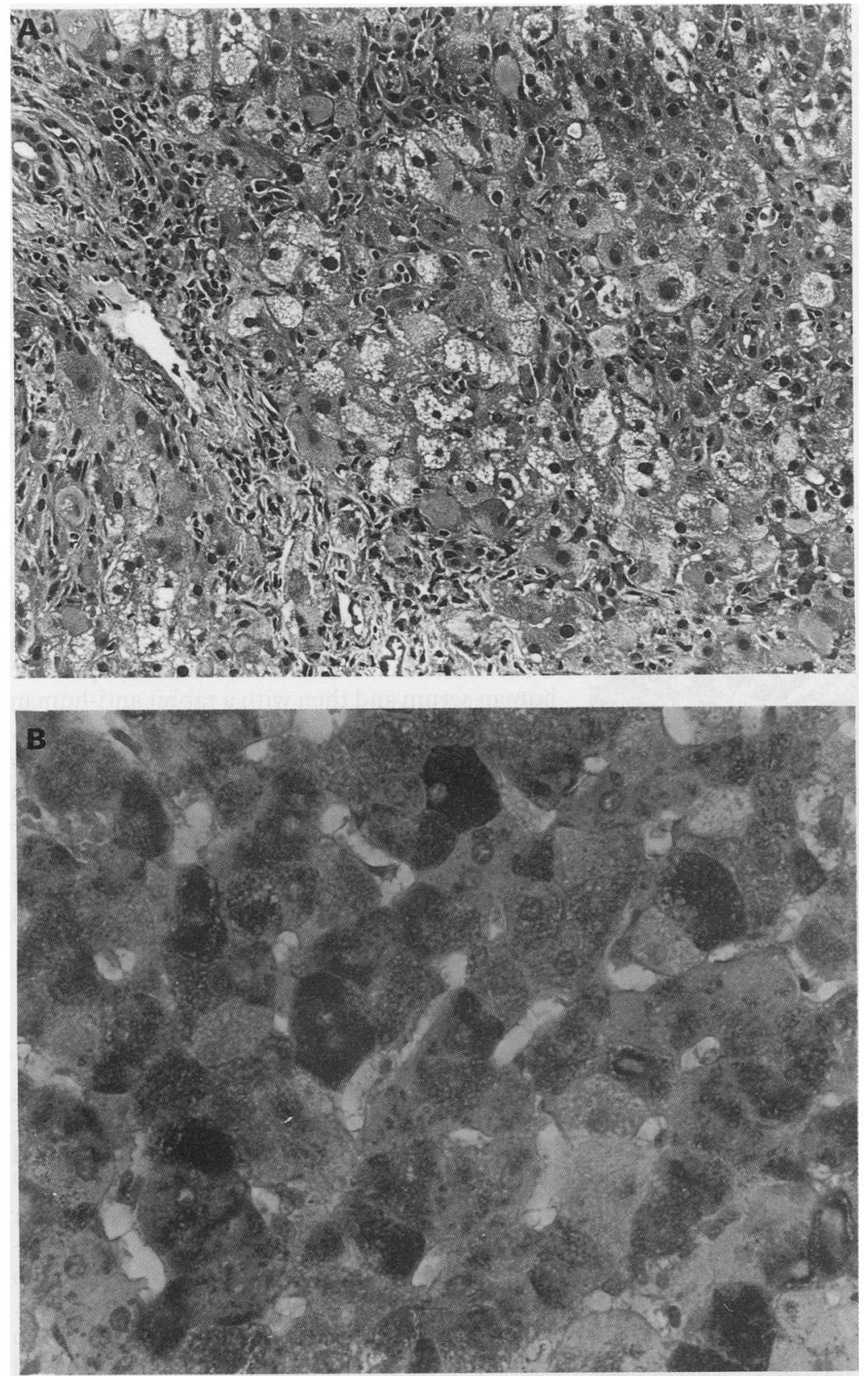

Figure 2: (A) Disorganised lobules contain appreciably swollen, distorted hepatocytes and scattered foci of necrosis. This biopsy specimen was obtained 15 months after transplant from a patient who died of liver failure and sepsis two months later. (Haematoxylin and eosin; original magnification $\times 200$. $)(B)$ Immunohistochemical stain for hepatitis $B$ surface antigen shows diffuse cytoplasmic staining. (Original magnification $\times 200)$.

positivity was 91 days, range 23-331 (Table II). Five of these patients who underwent seven transplants died. Survival at one and two years, as estimated by life table analysis, was $73 \%$ and $67 \%$ respectively. In all of these patients, recurrent $\mathrm{HBV}$ was a major contributing factor to death, sometimes complicated by other infections or reoperation.

Four of five patients with previous HBV and HDV infections developed serum $\mathrm{HBsAg}$ or HBV DNA, or both after transplantation after intervals of 14 days in two patients, and 60 and 90 days in two patients. HDAg was detected by immunohistochemistry in three grafts at 4,8 , and 37 days respectively after transplantation. The actuarial survival of patients with both HBV and $\mathrm{HDV}$ in their native liver was $100 \%$ at one and two years.

All patients who became serum HBsAg posi- tive after transplant, became $\mathrm{HBeAg}$ positive irrespective of $\mathrm{HDV}$ infection. Five of 12 patients with $\mathrm{HBV}$ infected allografts developed progressive liver damage. Serial biopsy specimens of the liver allografts in four of these patients showed a sequence beginning with hepatocyte enlargement and induction like changes leading to the formation of rigid hepatocyte cords aligned in parallel (Fig 1A). HBcAg was usually the first viral antigen to be detected by immunohistochemistry (Fig 1B). Next, the hepatocytes became considerably enlarged and contained the typical HBV type ground-glass inclusions. The inclusions were cytoplasmic, eccentric to and sometimes partly surrounding the nucleus, and were composed of finely granular pale material which seemed to retract from the cell membrane, leaving a partial clear zone between membrane and inclusion. Immunohistochemistry showed that these distorted hepatocytes stained intensely for cytoplasmic HBsAg and cytoplasmic and nuclear $\mathrm{HBcAg}$ (Fig 2A, B). Intracellular and canalicular cholestasis, as well as periportal ductular proliferation always accompanied these cellular changes as the disease progressed. Despite the striking lobular disorganisation and prominent hepatocellular changes, there was only mild inflammation. Fibrosis was variable, ranging from subtle, thin periportal and perisinusoidal collagen fibres to diffuse periportal and panlobular pericellular fibrosis (Fig 3). In two cases there were foci of confluent lobular necrosis and haemorrhage, presumably because of superimposed ischaemia. All four patients who developed this sequence of biopsy changes died, including one patient in whom this pattern occurred in two allografts. The median interval from identification of fibrosing cholestatic hepatitis to death or transplantation was 53 days, range 35 to 85 days.

One additional patient with $\mathrm{HBV}$ alone before the transplant, rapidly developed HBV graft infection as shown by stainable $\mathrm{HBcAg}$ in a biopsy specimen taken only six days after transplantation. Another biopsy specimen taken 22 days later showed the 'rigid cord pattern' described above. This was followed by a noninflammatory $\mathrm{HBV}$ carrier state at 27 weeks (Fig 4) and a mild persistent hepatitis 33 weeks after transplantation. Subsequent biopsy specimens taken at 19, 25, and 41 months showed a quiescent cirrhosis with $\mathrm{HBcAg}$ and $\mathrm{HBsAg}$ in scattered hepatocytes (Fig 5). He is currently alive 43 months after transplantation.

Seven patients with $\mathrm{HBV}$ infected allografts had a mild clinical disease. Five of these seven patients were also infected with HDV before transplantation, and recurrent HDV was documented in three. The mild clinical disease corresponded with either a persistent or smouldering lobular hepatitis or a non-inflammatory HBV carrier state. Serial biopsy specimens in these patients often showed variations in the intensity of inflammation and hepatocyte necrosis. There was no consistent pattern to the liver enzyme activities which corresponded to the appearance of HBsAg or HBV DNA in serum or HBsAg or $\mathrm{HBcAg}$, or both, in liver. The reappearance of serum markers of $\mathrm{HBV}$ often occurred while 


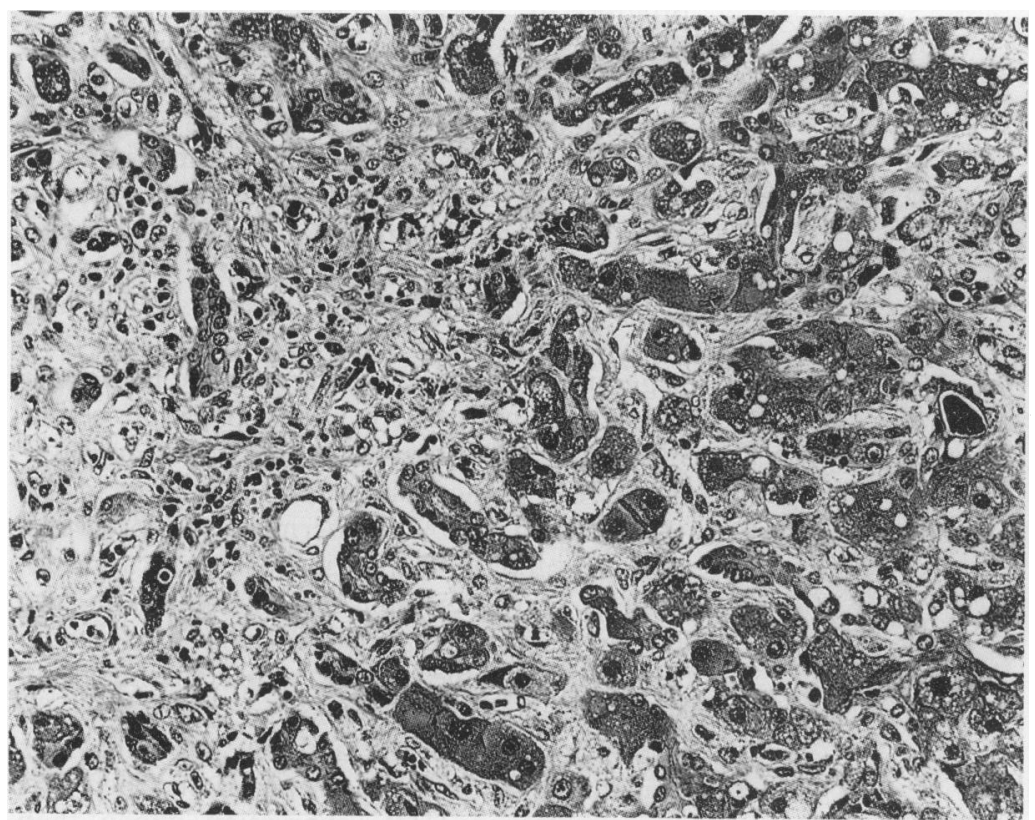

Figure 3: Progressive hepatitis $B$ virus antigen accumulation was accompanied by cholestasis and striking pericellular fibrosis in this transplanted liver. The patient died of liver failure and sepsis eight months after transplant. (Trichrome: original magnification $\times 200$ ).

serum transaminases activities were at or near normal. However, two of the patients with HBV and HDV showed a distinct clinical hepatitic syndrome about 12 weeks after transplantation. Malaise and appreciable increases in serum transaminase activities coincided with a marked increase in the number of hepatocytes staining for HDAg and also the first histological appearance of $\mathrm{HBcAg}$ (Fig 6). In one patient, this was accompanied by a histological pattern of acute viral hepatitis, whereas there was only an exacerbation of mid-lobular hepatitis in the other. Both patients were given a course of $\mathrm{OKT}_{3}$. This was followed by a decline and then a second smaller peak in serum transaminase activities. Immunohistochemistry showed persistent HDAg and

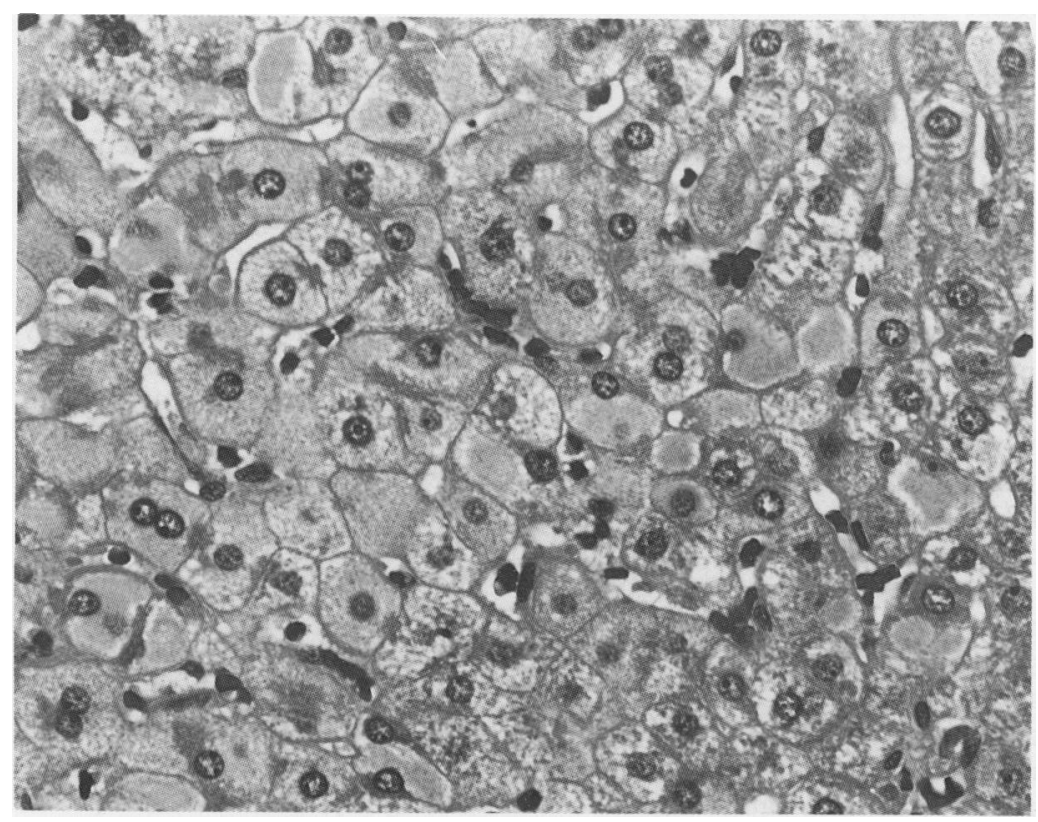

Figure 4: Hepatitis B virus carrier strate is characterised by numerous ground glass hepatocytes which contain abundant intracytoplasmic hepatitis $B$ surface antigen. Most liver cells contain hepatitis B core antigen in their nuclei and cytoplasm. (Haematoxylin and eosin; original magnification $\times 400$.)
$\mathrm{HBcAg}$ within hepatocytes. This rebound hepatitis resolved to a plateau of moderately abnormal transaminase activities and histological features of chronic persistent hepatitis and continued staining of hepatocytes for $\mathrm{HBsAg}, \mathrm{HBcAg}$, and HDAg without further adjustments in immunosuppression.

Three patients originally infected with HBV alone did not develop serological or biopsy evidence of $\mathrm{HBV}$ graft infection at 8,16 , and 17 months after transplantation, respectively. One of these patients, whose postoperative course was complicated by systemic cytomegalovirus infection, developed smoldering lobular hepatitis seen in biopsy specimens obtained 45,125 , 229, and 240 days after transplant. Progressive cholestasis accompanied the hepatitis in the final two biopsy specimens. Testing for serum antiHCV was not performed. The patient died of liver and pulmonary failure caused by cytomegalovirus and aspergillosis on day 242. Another patient developed a persistent hepatitis of unknown aetiology at six months followed by a normal biopsy specimen at 15 months. The third patient has declined a liver biopsy since day 68 after transplant, at which time the graft showed lobular disorganisation without inflammation.

Patients were stratified according to whether recurrent $\mathrm{HBV}$ caused severe, progressive liver injury, including cirrhosis, or mild liver disease (see Table III). Progressive disease was more common in older recipients and among patients with active inflammation and $\mathrm{HBcAg}$ in their native livers. Progressive disease did not occur in the infected allograft when the corresponding native livers showed quiescent cirrhosis or massive necrosis. Coinfection of the allograft by $\mathrm{HBV}$ and $\mathrm{HDV}$ was always associated with a mild disease and prolonged survival. Eight of 10 patients who received HBIG and 5 of 6 who did not receive HBIG developed serological markers of active HBV infection. The median duration to the development of HBV markers in serum or liver was 78 days (range 14-331) in patients receiving HBIG compared with 39 days (range 6-219) in those who did not receive HBIG. The median time to detection of $\mathrm{HBV}$ infection was 33 days (range 6-224) in the five patients who received six grafts which developed progressive liver injury (fibrosing cholestatic hepatitis or cirrhosis) compared with 39 days (range 26-331) in seven patients with recurrent HBV associated with mild liver disease.

Sera taken before and after transplantation have been tested retrospectively for anti-HC Ab in 12 patients. Ten were positive preoperatively and eight postoperatively. Neither patient who was negative before transplantation developed anti-HC $\mathrm{Ab}$ after transplantation.

\section{Discussion}

This study describes the clinical events that occur when $\mathrm{HBV}$, with or without HDV, infects the transplanted liver. Starzl et al reported on liver transplantation in 52 adult patients with HBV infection in whom the 24 month survival was $50 \%$ compared with $76 \%$ in 744 adult liver recipients with non-malignant disease.' These and other authors have found that recurrence of 


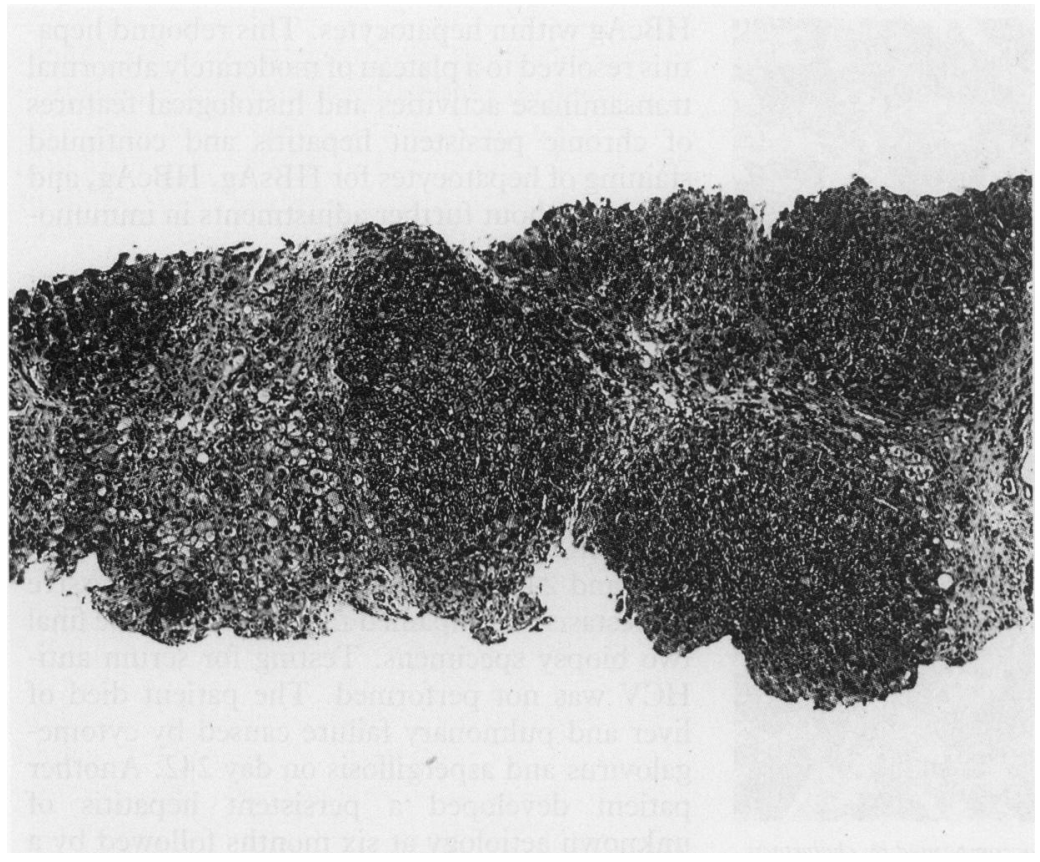

Figure 5: Quiescent cirrhosis was diagnosed in a single liver 19 months after transplant. Earlier biopsy specimens from this transplanted liver showed hepatitis $B$ virus reinfection (Figs 1 and 4 ), but minimal inflammation or necrosis. (Trichrome; original magnification $\times 40$.)

HBV in the grafted liver is very frequent. ${ }^{1-5}{ }^{11-14}$ Our experience in a smaller series is almost identical, in that HBV infection occurred in 13 of 16 grafts and death occurred in 5 of 10 patients whose grafts were infected with HBV alone.

Our data show that recurrent $\mathrm{HBV}$ infection is accompanied by a variety of disease patterns in the transplanted liver. One form, which seems unique to the infected allograft, was seen in four of our patients. Severe rapidly progressive liver disease was associated with the following histopathological features: distorted ground glass hepatocytes laden with $\mathrm{HBsAg}$ and $\mathrm{HBcAg}$, cholestasis, a variable degree of fibrosis, and in some cases, lobular necrosis. This pattern is indistinguishable from 'fibrosing cholestatic hepatitis' described by Davies et al, and like them we found it to portend a bad prognosis. ${ }^{4}$ The Pittsburgh group also described a similar constellation of findings and noted that HBV infection seems to progress more rapidly when it recurs in a second allograft..$^{23}$ This was also our experience in one patient in whom 'fibrosing cholestatic hepatitis' was seen in the first transplant at 20 weeks and progressed to require retransplantation at 32 weeks. Thereafter, a similar histological pattern evolved rapidly in the second allograft from which biopsy specimens were taken at 14,26 , and 32 days. This patient died of liver failure 2 i.ionths after the second operation.

We observed a gradual progression to cirrhosis in one HBV infected allograft. The initial biopsy specimens in that patient also passed through the stages seen in our allografts which eventually developed 'fibrosing cholestatic hepatitis' namely hepatocytes in rigid cords and later distorted ground glass hepatocytes. It is unclear what factors dictate whether an infected liver in which there are early signs of tissue injury will progress to 'filbrosing cholestatic hepatitis' or cirrhosis. The progression to cirrhosis in our patient occurred despite the lack of significant inflammation.

In contrast, many allografts became infected with $\mathrm{HBV}$ without developing significant tissue injury. A benign clinical course was associated with: absence of immunoreactive $\mathrm{HBcAg}$ or active cirrhosis in the native liver, as well as the presence of HDAg in the native liver. These data suggest that the risk of liver damage is greatest in patients with active viral replication before operation. HDV may be protective by suppressing HBV replication in the native and in the transplanted liver. ${ }^{15}$ Furthermore, we observed a curious biphasic hepatitis beginning approximately 12 weeks after transplantation in two patients coinfected with HBV and HDV which resolved to stable chronic persistent hepatitis. This acute syndrome coincided with a surge in expression of both HBV and HDV proteins. One explanation of this phenomenon is that there was an increase in HDV expression which then suppressed HBV expression allowing a stable equilibrium to develop between the two viruses and the liver. ${ }^{15}$

Our data do not allow us determine whether HBIG is beneficial in preventing or ameliorating recurrent HBV. However, recent evidence suggests that HBIG may reduce the frequency, or extend the time to onset, of recurrent HBV..$^{12}$ Indeed Samuel et al reported that when HBIG was administered on a regular basis in the first two years after liver transplantation to 110 patients who had been serum HBsAg positive, $\mathrm{HBsAg}$ reappeared in $22 \cdot 7 \%$ only. ${ }^{1+}$ However, since the reappearence rate was much higher $(96 \%)$ in patients with evidence of active viral replication (serum HBV DNA positive), and since our data would suggest that the severity of injury in the infected allograft is also dependent on the HBV status of the native liver, the efficacy of repeated administration of HBIG deserves to be tested within a randomised controlled trial.

The frequent recurrence of $\mathrm{HBV}$ and $\mathrm{HDV}$ in liver allografts raises interesting questions about the source of HBV and HDV. We presume that those patients who manifested $\mathrm{HBV}$ in the allograft within days of transplantation acquired it from virus shed into the blood stream before or during the operation. Similarly, the very short time taken for HDAg to appear in three grafts suggests it was spread perioperatively. However, in some patients there was a considerable delay before markers for HBV infection were found. This may be a phenomenon of test sensitivity in which infection of the graft occurred perioperatively in these patients also. However, in a series of $\mathrm{HBsAg}$ positive patients undergoing liver transplantation Feray et al found HBV-DNA genome sequences in peripheral blood mononuclear cells in 7 of 11 liver transplant recipients who were serum HBsAg negative and liver HBVDNA negative by polymerase chain reaction postoperatively." Extrahepatic HBV-DNA sequences have been observed in human autopsy specimens including lymph nodes, spleen, kidney, pancreas, brain, and endocrine tissues. ${ }^{16}$ Thus, HBV infected extrahepatic tissues, including peripheral blood mononuclear cells, 


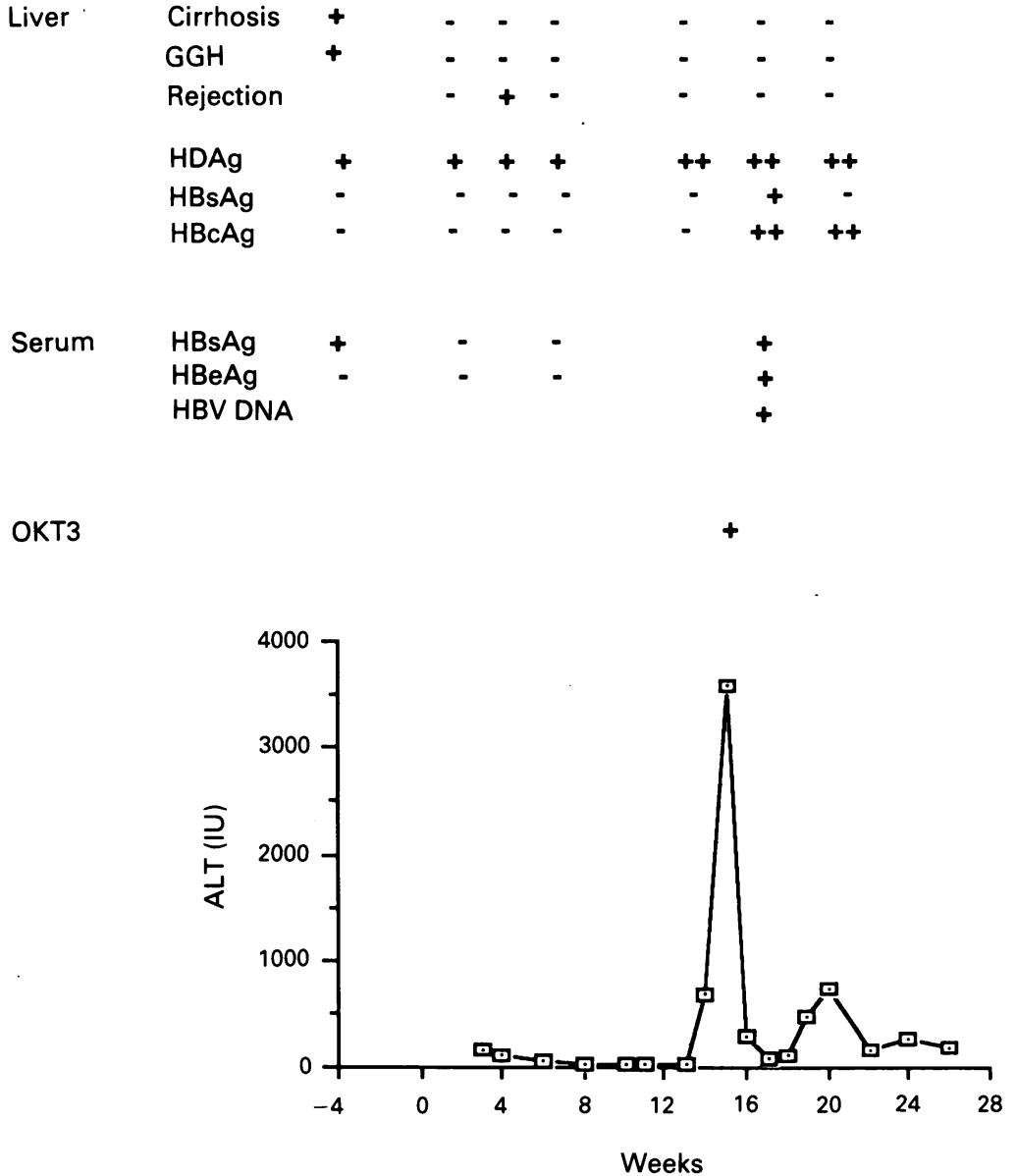

Figure 6: Clinical sequence in a patient with hepatitis $B$ and $D$ virus infection demonstrating coincidence of acute inflammatory pattern of liver enzymes with increased expression of hepatitis $B$ and hepatitis $D$ viral proteins within the grafted liver. Week 0 on the abscissa indicates the time of liver transplantation. GGH refers to large ground glass hepatocytes. $\mathrm{OKT}_{3}$ indicates a 10 day course of orthoclone $\mathrm{OKT}_{3}$ (see text).

may be important potential sources for late infection of the graft.

The evidence that HBV infection can cause severe liver damage in liver transplant recipients who are immunosuppressed suggests that cellular immunity may not be the sole mechanism for $\mathrm{HBV}$ associated liver injury and agrees with data on HBV infections in other immunosuppressed states. ${ }^{17}{ }^{18} \mathrm{~A}$ common feature that we observed in HBV infected liver transplants was an abundance of distorted ground glass hepatocytes. These contain HBsAg and both nuclear and cytoplasmic $\mathrm{HBcAg}$, signifying intense viral replication. ${ }^{19}$ One explanation for this unbridled production of $\mathrm{HBV}$ proteins is that it is fostered by concurrent medications, including glucocorticoids and cyclosporin. Tur-Kaspa et al have identified a glucocorticoid responsive expression enhanced element in the HBV genome. ${ }^{20}$ The effect of cyclosporin on HBV has not been

TABLE III Factors influencing clinical outcome in 15 patients with hepatitis $B$ virus $(H B V)$ including five with concomitant hepatitis $D$ virus $(H D V)$

\begin{tabular}{|c|c|c|c|c|c|c|}
\hline$H B V$ in allograft & No & $\begin{array}{l}\text { Age at } \\
\text { transplant } \\
\text { (years) }\end{array}$ & $\begin{array}{l}\text { Histopathology of } \\
\text { native liver }\end{array}$ & & $\begin{array}{l}H B c A g \text { in } \\
\text { native liver }\end{array}$ & $\begin{array}{l}H D A g \text { in } \\
\text { native liver }\end{array}$ \\
\hline $\begin{array}{l}\text { Reinfected, mild } \\
\text { disease }\end{array}$ & 7 & 32 & $\begin{array}{l}\text { Active cirrhosis } \\
\text { Quiescent cirrhosis } \\
\text { Massive necrosis }\end{array}$ & $\begin{array}{l}1 \\
4 \\
2\end{array}$ & 0 & 5 \\
\hline $\begin{array}{l}\text { Reinfected, severe } \\
\text { disease } \\
\text { No evidence of } \\
\text { reinfection }\end{array}$ & 5 & 48 & $\begin{array}{l}\text { Active cirrhosis } \\
\text { Active cirrhosis } \\
\text { Quiescent cirrhosis }\end{array}$ & 1 & 2 & 0 \\
\hline
\end{tabular}

studied, although it is interesting that when cyclosporin was administered to woodchucks who were infected with a related hepadnavirus, it resulted in a significantly more severe hepatitis and sustained viraemia than in non-cyclosporin treated controls. ${ }^{21}$ The increased expression of HBV proteins, especially pre $S^{1}$ proteins, in the present patients probably perturbs the process whereby $\mathrm{HBsAg}$ is secreted by the infected hepatocyte. ${ }^{22} \mathrm{~A}$ comparable phenomenon has been described in a transgenic mouse model which produces long segments of HBsAg including pre $S^{1}$ proteins and which eventually develops distorted ground glass hepatocytes very similar to those in the present liver transplant recipients. ${ }^{23}$ It is uncertain whether the development of these ground glass hepatocytes is a benign phenomenon or is linked with the progression to liver damage. In the transgenic mouse model, hepatocellular damage, including multinodular regenerative hyperplasia, raised transaminase activities and eventual tumour formation have been described. It is of interest, therefore, that de novo development of a hepatoma has been reported in a liver allograft infected with $\mathrm{HBV} .^{2+}$

The authors thank Mrs Muriel Fritz for assistance in preparing this manuscript. This work was presented in part to the digestive disease week of the American Gastroenterological Association, May 1989, and published in abstract: Gastroenterology 1989; 96: A624.

1 Starzl TE, Demetris AJ, VanThiel D. Liver transplantation. N Engl f Med 1989; 321: 1014-22, 1092-9.

2 Demetris AJ, Todo S, Van Thiel DH, Fung JJ, Iwaki Y, Sysyn $\mathrm{G}$, et al. Evolution of hepatitis virus liver disease after hepatic replacement: practical and theoretic considerations. Am F Pathol 1990; 137: 667-76.

3 Todo S, Demetris AJ, Van Thiel D, Teperman L, Fung JJ, Starzl TE. Orthotopic liver transplantation for patients with hepatitis B virus-related liver disease. Hepatology 1991; 13 : 619-26.

4 Davies SE, Portmann BC, O'Grady JG, Aldis PM, Chaggar K, Alexander GJM, et al. Hepatic histologic findings after transplantation for chronic hepatitis virus infection, including a unique pattern of fibrosing cholestatic hepatitis. ing a unique pattern of

5 Rizzeto $M$, Chiaberge E, Negro F, di Giacono C, Cortesini R, Doglia $M$, et al. Liver transplantation in hepatitis delta virus Doglia M, et al. Liver transplanta

6 Turcotte JG, Campbell DA, Merion RM, Burtch GD, Ham JM. Hepatic transplantation. In: Zuidema GB, Turcotte JG, eds. Surgery of the alimentary tract. Philadelphia: WB Saunders, 1991: 494-506.

7 Kaneko S, Miller RH, Di Bisceglie AM, Feinstone SM, Hoofnagle JH, Purcell RH. Detection of hepatitis B virus DNA in serum by polymerase chain reaction. Gustroenterology 1990; 99: 799-804.

$8 \mathrm{Hsu}$ S-M, Raine K, Fanger H. Use of avidin-biotin-peroxidase complex $(\mathrm{ABC})$ in immunoperoxidase techniques: a comparison between ABC and unlabeled antibody (PAP) proparison between ABC and unlabeled antibody

9 Recchia S, Rizzi R, Acquaviva F, et al. Immunoperoxidase staining of the HBVL-associated delta antigen in parafinated lived specimens. Pathologica 1981; 73: 773-7.

10 Merion RM, Delius RE, Campbell DA, Turcotte JG. Orthotopic liver transplantation totally corrects factor IX deficiency in hemophilia B. Surgery 1988; 104: 929-31.

11 Feray C, Zignego AL, Samuel D, et al. Persistent hepatitis B virus infection of mononuclear blood cells without concomitant liver infection. Transplantation 1990; 49: 1155-8.

12 Mora NP, Klintmalm GB, Poplawski SS, et al. Recurrence of hepatitis B after liver transplantation: does hepatitis-Bimmunoglobulin modify the recurrent disease? Transplant Proc 1990; 22: 1549-50.

13 Martin P, Munoz SJ, Di Bisceglie AM, et al. Recurrence of hepatitis $C$ after liver transplantation. Hepatology 1991; 13: 719-21.

14 Samuel D, Bismuth A, Mathieu D, Arulnaden J-L, Reynes M Benhamou J-P, et al. Passive immunoprophylaxis after liver transplantation in HBsAg-positive patients. Lancet 1991; transplantacion $813-5$.

15 Genesca J, Jardi R, Buti M, et al. Hepatitis B viral replication in acute hepatitis $B$, acute hepatitis $B$ virus-hepatitis delta virus coinfection and acute hepatitis delta superinfection. Hepatologv 1987; 7: 569-72.

16 Yoffe B, Burns DK, Bhatt HS, Combes B. Extrahepatic hepatitis $B$ virus DNA sequences in patients with acut hepatitis B infection. Hepatologv 1990; 12: 187-92. 
17 Wands JR, Chura CM, Roll FJ, Maddrey WC. Serial studies of hepatitis-associated antigen and antibody in patients receiving antitumor chemotherapy for myeloproliferative and lymphoproliferative disorders. Gastroenterology 1975; 68: 105-12.

18 Degos F, Lugassy C, Degott C, et al. Hepatitis B virus and hepatitis B-related viral infection in renal transplant recipients. A prospective study of 90 patients. Gastroenterology 1988; 94: 151-6.

19 Roingeard P, Lu S, Sureau C, et al. Immunocytochemical and electron microscopic study of hepatitis $B$ virus antigen and complete particle production in hepatitis B virus DNA complete particle production in hepatitis B virus

20 Tur-Kaspa R, Burk RD, Shaul Y, Shafritz DA. Hepatitis B virus DNA contains a glucocorticoid-responsive element. Proc Natl Acad Sci USA 1986; 83: 1627-31.
21 Cote PJ, Korba B, Tennant BC, Gerin JL. Immunopathogenesis and immunomodulation of Woodchurch hepatitis virus infection. In: Hollinger FB, Lemon SM, Margolis HS. Viral hepatitis and liver disease. Baltimore: Williams and Wilkins, 1991: 244-51.

22 Pershing DH, Varmus HE, Ganem D. Inhibition of secretion of hepatitis B surface antigen by a related presurface polypeptide. Science 1986; 234: 1388-91.

23 Chisari FV, Filippi P, Buras J, et al. Structural and pathological effects of synthesis of hepatitis B virus large envelope polypeptide in trans:
$1987 ; 84: 6907-13$.

24 Luketic VA, Shiffman ML, McCall JB, Posner MP, Mills AS, Carrithers RL. Primary hepatocellular carcinoma after orthotopic liver transplantation for chronic hepatitis B infection. Ann Intern Med 1991; 114: 212-3. 